periods will have a beneficial effect on persons whose duties require aggressive ascent profiles. Such modifications in working conditions are not construed as a substitute for conservative ascents, but as a harm reduction approach to reduce the documented hazards associated with this occupation.

Anne M. Anglim, MD, MS Helena, MT, USA

Daniel W. Boyd, MS Kirksville, MO, USA

\section{Skiing and Snowboarding-related Head Injuries in the United States: A Retrospective Analysis From 2004-2010}

Background.-Skiing and snowboarding-related head injuries are frequently encountered by medical providers in a wilderness setting.

Objective.-The purpose of this analysis was to determine the scope, trends, and characteristics of skiing and snowboarding-related head injuries across the United States during 6 winter seasons from 2004 to 2010.

Methods.-A retrospective analysis was conducted using data from the National Electronic Injury Surveillance System (NEISS). Sample weights were used to calculate national estimates of head injuries related to skiing and snowboarding. Narratives provided were used to characterize injury context and severity as well as identify prevalence of helmet use.

Results.-An estimated 68761 patients with head injuries sustained while skiing or snowboarding presented to emergency departments from 2004 to 2010. This estimate was calculated from 1629 cases registered in NEISS. The number of head injuries increased from 9308 in 2004 and 2005 to 14947 in 2009 and 2010, while the incidence of non-head-related injuries remained steady. Children (younger than 10 years old) were the only age group to show a decreased proportion of head injuries over the 6 seasons, from $11.7 \%$ to $4.6 \%$. Males accounted for $68.8 \%$ of head injuries and snowboarders for $57.9 \%$ of head injuries. Riders aged 11 to 17 years old sustained a greater proportion of head injuries $(47.7 \%)$ than did any other age group. The most common diagnosis was concussion $(67 \%)$. More than 1 in 10 patients required hospitalization. Helmet use was noted in approximately one-third of the narratives. The percentage of helmeted riders injured increased from $36.7 \%$ to $57.9 \%$ over the 6-year period, which correlates with National Ski Areas Association data on increases in helmet use in the general population.

Conclusions.-Skiing and snowboarding-related head injuries increased from 2004 to 2010 at a higher rate than all other ski and snowboard-related injuries despite a significant increase in helmet use. The proportion of head injuries among children, however, has decreased. Males, snowboarders, and teenagers are most likely to be injured.

Mark L. Christensen, DO Collin Jackson, MD Kalamazoo, MI, USA

\section{Brokeback Mountain: Spinal Injuries in Mountain} Casualties in Snowdonia

Background.-Our emergency department (ED) receives casualties from Snowdonia National Park and surrounding areas. Suspected spinal injuries are common in mountain casualties and pose handling challenges for rescue personnel.

Objective.-The pattern and severity of spinal injuries occurring among UK mountain casualties has not been well studied. Therefore, we wished to establish the incidence and pattern of spinal injuries in mountain casualties presenting to our hospital.

Methods.-Cases with spinal fractures were identified from our database of mountain casualties brought to our ED January 2004 to December 2011 after contact with mountain rescue teams or Royal Air Force Search and Rescue helicopter, or both. Radiological reports and images were reviewed to establish vertebral level and type of injury.

Results.-Of 789 mountain casualties during the study period, $636(80 \%)$ were injured rather than ill, although 196 had only isolated lower leg injuries. Fifty-one cases had confirmed spinal fractures, including 8 fatalities $(17.4 \%$ of the 46 trauma fatalities). Most of the spinal fractures (44 of 51) had fallen from a height greater than standing; 20 were direct and 24 were tumbling falls. Most were rock climbing or hill walking at the time of incident. Forty-three of 394 nonisolated ankle trauma casualties $(11 \%)$ had spinal fractures, but only 7 of 43 were unstable: the unstable fracture rate in casualties found alive was $1.8 \%$. Only 1 survivor sustained spinal cord damage, compared with 5 of 8 fatalities (56\%); T12 and L1 together accounted for $43 \%$ of spinal fractures.

Conclusions.-Spinal fractures are quite common in mountain casualties in North Wales. However, only $1.8 \%$ of casualties still alive when help arrived had unstable spinal fractures, and only 1 casualty sustained spinal cord injury. Direct falls (eg, rock climbing) produce a similar injury pattern as for urban fallers, but falls of a tumbling nature were associated with a higher rate of cervical and thoracic injury and a greater mortality among fallers with spinal injuries.

\section{Sebastian Wills Cardiff, Wales, UK}

Benjamin G. R. Hall, MBChB, MCEM Linda K. Dykes, MBBS (Hons), FCEM Bangor, North Wales, UK

\section{Tourist Mountain: Mountain Casualties in Snowdonia}

Background.-The Snowdonia mountain range in North-West Wales (United Kingdom) attracts millions of visitors each year.

Objective.-This retrospective study examined the characteristics of mountain casualties brought to the local emergency department (ED) in Bangor, having been rescued by the local Mountain Rescue Teams (MRT) or the hoist-equipped Royal Air Force Search and Rescue (RAF SAR) helicopter.

Methods.-Mountain rescues (including from coastal cliffs) resulting in attendance at our ED over an 8-year period (January 2004 to December 2011) were identified using MRT and 